\author{
RESEARCH ARTICLE \\ 10.1029/2018JC014508 \\ Key Points: \\ - The North Atlantic subtropical \\ surface salinity maximum expanded \\ northward \\ - Subduction of the Subtropical \\ Underwater was shifted northward \\ and intensified \\ - Volume of the Subtropical \\ Underwater mainly increased from \\ April to June
}

Correspondence to:

H. Liu,

liuhao9349@stu.edu.cn

Citation:

Liu, H., Yu, L., \& Lin, X. (2019). Recent decadal change in the North Atlantic Subtropical Underwater associated with the poleward expansion of the surface salinity maximum. Journal of Geophysical Research: Oceans, 124, 4433-4448. https://doi.org/10.1029/ 2018JC014508

Received 24 AUG 2018

Accepted 4 JUN 2019

Accepted article online 11 JUN 2019

Published online 2 JUL 2019

(C)2019. American Geophysical Union. All Rights Reserved.

\section{Recent Decadal Change in the North Atlantic Subtropical Underwater Associated With the Poleward Expansion of the Surface Salinity Maximum}

\author{
Hao Liu' ${ }^{1}$, Lisan Yu$^{2}$ (D) and Xiaopei Lin ${ }^{1}$ (D) \\ ${ }^{1}$ Physical Oceanography Laboratory/CIMST, Ocean University of China and Qingdao National Laboratory for Marine \\ Science and Technology, Qingdao, China, ${ }^{2}$ Woods Hole Oceanographic Institution, Woods Hole, MA, USA
}

Abstract Yu et al. (2017, https://doi.org/10.1002/2017GL075772) reported that the annual mean sea surface salinity maximum (SSS-max) in the North Atlantic expanded northward by $0.35 \pm 0.11^{\circ}$ per decade over the 34-year data record (1979-2012). The expansion shifted and expanded the ventilation zone northward and increased the production of the Subtropical Underwater (STUW). As a result, the STUW became deeper, thicker, and saltier. In this study, the seasonal characteristics of the poleward expansion of the North Atlantic SSS-max and their effects on the STUW are examined. The results show that the SSS-max expansion occurred primarily during boreal spring (April, May, and June) and expanded northward by $0.43 \pm 0.21^{\circ}$ per decade over the 34-year period. The annual volume of the STUW increased by $0.21 \pm 0.0910^{14} \mathrm{~m}^{3}$ per decade over the same period, and the spring (April, May, and June) volume increased by $0.31 \pm 0.0210^{14} \mathrm{~m}^{3}$ per decade (a relative increase of $48 \pm 1 \%$ ). The characteristics of the decadal changes in STUW were attributable to the increased subduction rate associated with the northward expansion of the SSS-max. The annual subduction rate increased by $0.29 \pm 0.07 \mathrm{~Sv}$ per decade over the 34 years, and the greatest increase of $1.73 \pm 0.61 \mathrm{~Sv}$ per decade occurred in April. The change in subduction associated with the expansion of the SSS-max appeared to be consistent with the Atlantic Multidecadal Oscillation.

\section{Introduction}

The sea surface salinity (SSS) in the global subtropical gyres has been increasing at a rate of 0.01 to 0.03 on the practical salinity scale (PSS-78) per decade (Antonov et al., 2002; Curry et al., 2003; Boyer et al., 2005; Hosoda et al., 2009; Roemmich \& Gilson, 2009), and the largest increase has been observed in the subtropical North Atlantic Ocean (Durack et al., 2012; Durack \& Wijffels, 2010; Terray et al., 2012). Studies have suggested that the change of subtropical SSS might be a consequence of the increased evaporation-minus-precipitation (hereafter E-P) associated with the global warming (Durack et al., 2012; Durack \& Wijffels, 2010; Grodsky et al., 2006; Lago et al., 2015; Skliris et al., 2014; Terray et al., 2012). Two theories have been proposed to explain the response of the global hydrological cycle to rising global temperatures. One theory hypothesizes that the global hydrological cycle intensifies under a global warming trend (Held \& Soden, 2006; Zhou et al., 2011), thereby causing dry regions to become drier and wet regions to become wetter. The other theory is based on the observational findings of the poleward expansion of the Hadley Cell since 1979 (McCabe et al., 2001; Fyfe, 2003; Hudson et al., 2006; Hu \& $\mathrm{Fu}, 2007$; Hu et al., 2011). Consequently, the subtropical net evaporation zone has expanded, enhancing the poleward side of the E-P maxima (Scheff \& Frierson, 2012; Siler et al., 2018) primarily in boreal winter (Scheff \& Frierson, 2012).

The North Atlantic Subtropical Underwater (STUW) is formed under the SSS maximum (hereafter SSS-max) by subduction (O'Connor et al., 2005; Schmitt \& Blair, 2015), and the ventilation site is mainly located on the poleward side of the SSS-max in the North Atlantic Ocean (Yu et al., 2017). Yu et al. (2017) identified a poleward expansion of the annual mean SSS-max in the North Atlantic. During the analysis period of 1979-2012, the northern side of the SSS-max displaced northward by $1.2 \pm 0.36^{\circ}$, whereas the equatorward side of the SSS-max showed little change. Yu et al. (2017) found that the expansion shifted and expanded the ventilation zone of the STUW northward and northwestward, leading to a 35\% increase in the annual-mean production of the STUW. Their analysis was focused on the annual-mean perspectives of the SSS-max shift and its effects on the STUW. Seasonal characteristics of the connection between SSS-max and the STUW in the context of the poleward expansion have yet to be examined but are important for gaining a full understanding of the 
oceanic response to an expanding subtropics. Thus, this study aims to provide a detailed analysis of the seasonal characteristics of the change of the STUW associated with the poleward shift of the North Atlantic SSS$\max$.

This paper is organized as follows. Section 2 introduces a description of the data sets and methods used in the analysis. Section 3 examines the seasonal characteristics of the decadal expansion of the SSS-max and the associated changes in the STUW volume and thickness. Section 4 presents mechanisms responsible for the decadal changes of the STUW seasonality. A summary and conclusions are included in section 5 .

\section{Data and Methods}

\subsection{Data}

The main data set used in this analysis is the monthly objectively analyzed subsurface temperature and salinity data sets produced by Ishii et al. (2006). The Ishii data sets are compiled from the Centennial in situ Observation-Based Estimates of the SST, the World Ocean Database 2009, the Global TemperatureSalinity Profile Program, and Argo profiling float observations. The time series covers the period from 1945 to 2012 with a horizontal resolution of $1^{\circ} \times 1^{\circ}$ and 24 levels in the vertical. The 34-year period from 1979 to 2012 is used in the study.

The spatiotemporal coverage of the Ishii product is inhomogeneous because the number of SSS observations is sparse prior to 2002. To verify the seasonal characteristics of the poleward shift identified from the Ishii product, we resorted to two additional products. The first supplemental product is the monthly, $1^{\circ} \times 1^{\circ}$ binned SSS maps produced by L'Institut de recherche pour le développement (IRD) of the Laboratoire d'Etudes en Geophysique et Oceanographie Spatiale (LEGOS), Toulouse, France (Reverdin et al., 2007; http://www.legos.obs-mip.fr/observations/sss/datadelivery/products). The LEGOS SSS product covers the Atlantic, $95^{\circ} \mathrm{W}-20^{\circ} \mathrm{E}, 30^{\circ} \mathrm{S}-50^{\circ} \mathrm{N}$, and is compiled from the surface salinity measurements made along commercial ship lanes during the period from 1970 to 2016. The Ishii product blended salinity observations from various sources but did not include the surface data in the Atlantic collected by IRD/LEGOS (Ishii et al., 2006). Therefore, the LEGOS SSS product in the Atlantic Ocean can serve as an independent verification of the Ishii product.

The second supplemental product is the version 4 of the Met Office Hadley Centre EN (hereafter EN4) series of data sets of global quality-controlled ocean temperature and salinity profiles and monthly objective analysis (Good et al., 2013). The EN4 data set is gridded on $1^{\circ}$ boxes, with the vertical interval ranging from 5.02 to 5,350.3m nonuniformly. The topmost layer in EN4 is used for deriving variables at the sea surface. Unlike the Ishii product that provides no data sampling information, EN4 includes two sets of products. One is the $1^{\circ} \times 1^{\circ}$ gridded temperature and salinity monthly objective analysis with uncertainty estimates, and the other is the quality-controlled temperature and salinity profiles. The EN4 and Ishii products used similar data sources to cover the similar temporal period. The two EN4 products, the gridded and the profiles, are used to assess the potential impact of salinity sample density on the findings identified from the Ishii data sets.

\subsection{Methods}

The STUW criteria are adopted from O'Connor et al. (2005). The water mass in the North Atlantic is defined by a salinity range of 36.7-37.1, a temperature range of $20.4-22.4{ }^{\circ} \mathrm{C}$, and a potential density range of $25.6-26.3 \mathrm{~kg} / \mathrm{m}^{3}$. The annual mean subduction rate is calculated following the approach used in $\mathrm{Yu}$ et al. (2017):

$$
S=-\frac{1}{T} \int_{T_{1}}^{T_{2}}\left(\frac{\partial h}{\partial t}+\boldsymbol{u}_{b} \cdot \nabla h+w_{b}\right) d t
$$

where $h$ denotes the mixed layer depth, which is determined by the depth at which the potential density is $0.125 \mathrm{~kg} / \mathrm{m}^{3}$ larger than that at the sea surface (Monterey \& Levitus, 1997). $T$ represents 1 year, and $T_{1}$ and $T_{2}$ represent the times when effective detrainment starts and ends, respectively. The vertical and horizontal velocities at the bottom of the mixed layer are denoted by $w_{b}$ and $\boldsymbol{u}_{b}$, respectively, with $w_{b}$ being computed as follows: 


$$
w_{b}=w_{E K}-\frac{\beta}{f} \int_{h}^{0} v d z
$$

where the first term on the right hand denotes the Ekman pumping and the second term is the $\beta$ term. The Objectively Analyzed Air-Sea Fluxes for the Global Oceans (OAFlux) winds (Yu \& Jin, 2014) are used to compute the Ekman pumping. The velocity in the $\beta$ term and $\boldsymbol{u}_{b}$ are computed from the Ishii's salinity and temperature data. To estimate the monthly contribution to the annual subduction rate, equation (1) is transformed as follows:

$$
S_{i}=-\frac{1}{T_{i}} \int_{T_{i}}^{T_{i+1}}\left(\frac{\partial h}{\partial t}+\boldsymbol{u}_{b} \cdot \nabla h+w_{b}\right) d t
$$

where $i$ denotes the month. If the $i$ th month is within the effective detrainment period, then $S_{i}$ is nonzero; otherwise, $S_{i}$ is zero.

\section{Analysis}

\subsection{Observed Decadal Expansion of the SSS-max and Its Seasonal Characteristics}

The SSS-max is defined as the water mass enclosed by the surface 36.3 isohaline contour. Two proxies are used to identify the expansion of the SSS-max: the meridional shift in the isohalines between the 1980s and the 2000s and the decadal difference in salinity between these two decades. The decadal expansion of the SSS-max defined by the two proxies is shown for the four seasons (Figure 1): winter (January-February-March), spring (April-May-June), summer (July-August-September), and fall (OctoberNovember-December). The meridional mean position of the climatological SSS-max is located at approximately $25^{\circ} \mathrm{N}$. Consistent with the annual-mean pattern reported in Yu et al. (2017), the sea surface isohalines on the poleward side (between $25^{\circ} \mathrm{N}$ and $45^{\circ} \mathrm{N}$ ) of the SSS-max show a larger poleward movement than those on the equatorward side (between $15^{\circ} \mathrm{N}$ and $25^{\circ} \mathrm{N}$ ) of the SSS-max. On seasonal timescales, the poleward expansion of the SSS-max occurs in all seasons, with a maximum in spring.

A linear trend analysis is performed on four selected surface isohalines on the poleward side of the SSS-max (Figure 1). The selected isohalines start from the SSS-max center at the 37.1 isohaline and decrease poleward at intervals of 0.4 PSS-78. The poleward shift peaks in spring, during which the 37.1 isohaline shifts northward by $0.21 \pm 0.12^{\circ}$ latitude per decade, the 36.7 isohaline by $0.3 \pm 0.14^{\circ}$ latitude per decade, the 36.3 isohaline by $0.547 \pm 0.221^{\circ}$ latitude per decade, and the 35.9 isohaline by $0.665 \pm 0.362^{\circ}$ latitude per decade. The poleward shift in spring is associated with a 0.15 increase in salinity on the poleward side of the SSS-max, which is the strongest salinification among all four seasons.

In addition to the meridional expansion toward the north, the surface isohalines also expand toward the west. This westward expansion is evidenced clearly on the northern boundary of the 36.7 isohaline in winter and spring, during which the isohalines expand westward by as much as $1.47-2.94^{\circ}$ per decade (Figure 1a). In the other two seasons, the degree of westward expansion weakens slightly to approximately $0.29-0.88^{\circ}$ longitude per decade. The westward expansion enlarges the spatial extent of the SSS-max and causes an increase in the surface salinity in the west. However, a salinity increase in the vicinity of the Gulf Stream has been reported as a result of the intensification of the West Boundary Current (WBC; Yang et al., 2016). Given that the distance between the isohalines is narrow within the WBC, the effect of the WBC intensification on the areas outside of the western boundary is expected to be small.

The two proxies used to delineate the expansion of the SSS-max (Figure 1) are also applied to the zonal mean section, obtained from the averaging the salinity fields in the upper $300 \mathrm{~m}$ between $80^{\circ} \mathrm{W}$ and $0^{\circ} \mathrm{W}$ (Figure 2), to identify key decadal changes in the subsurface subtropical North Atlantic. A poleward shift in a manner similar to those at the surface is observed (Figure 2). Specifically, there is a clear shift for the subsurface isohalines located on the poleward side of the SSS-max core but barely any changes for the isohalines on the equatorward side of the SSS-max core. Seasonal variations in the degree of the expansion are also observed in the subsurface. Consistent with the seasonal changes of the surface isohalines, the subsurface 36.7-35.9 isohalines have greater northward displacements in winter and spring than in summer and fall. In addition, the subsurface salinification occurs poleward of $25^{\circ} \mathrm{N}$, with a peak in salinity anomalies of 0.1 to 0.12 in spring. 

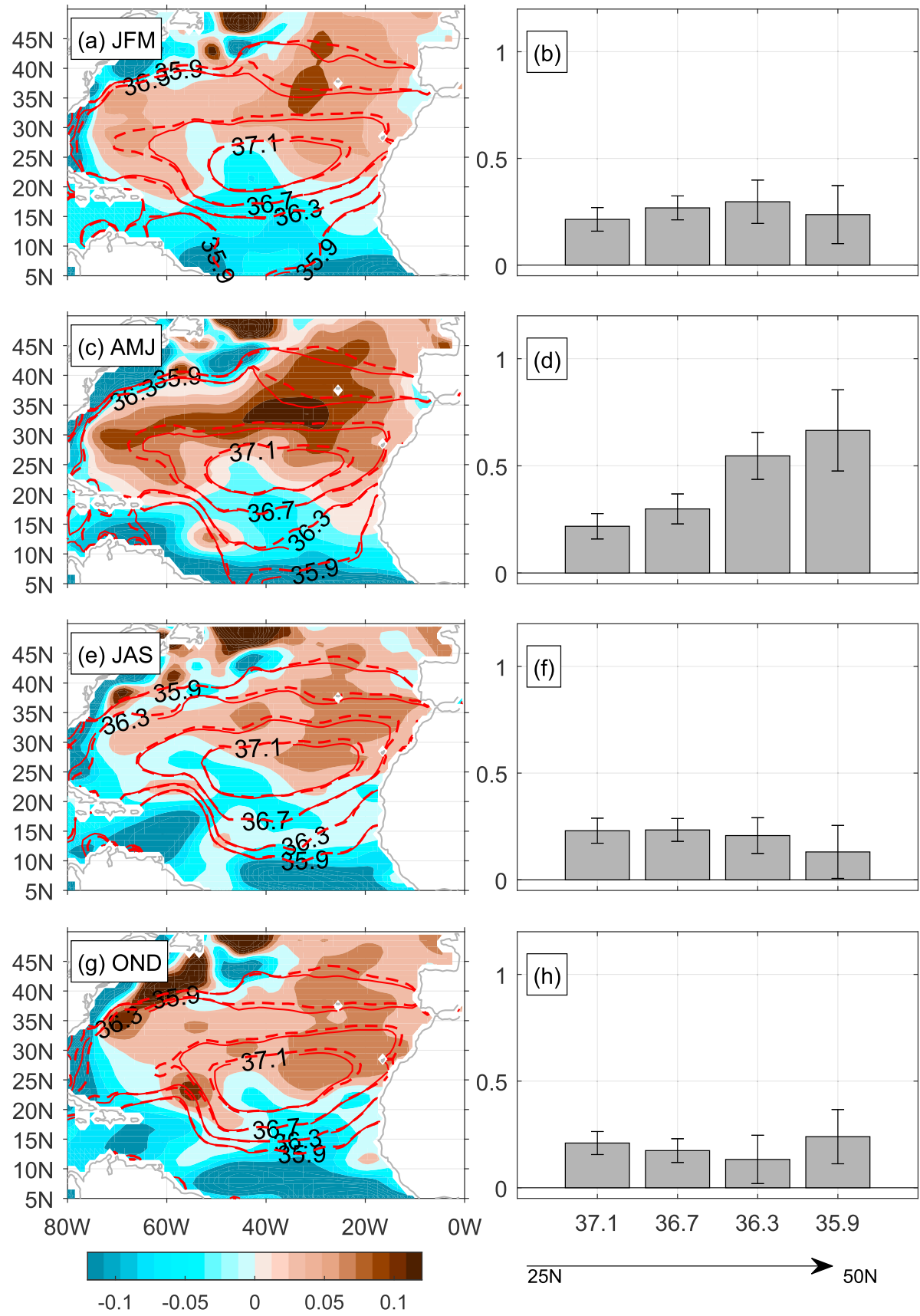

Figure 1. Decadal differences (2000-2009 minus 1980-1989; colors) in seasonally averaged surface salinity and the spatial isohaline shifts (contours) between the two decades for (a) winter (January-March), (c) spring (April-June), (e) summer (July-September), and (g) fall (October-December). The solid contours denote the isohalines averaged between 1980 and 1989, and the dashed contours denote the isohalines averaged between 2000 and 2009. The contour interval is 0.4. Bar plots of the linear trends of the poleward expansion of the isohalines on the poleward side of the SSS-max for (b) winter, (d) spring, (f) summer, and (h) fall. The error bars denote the $90 \%$ confidence levels, which are derived from a two-tailed Student's $t$ test. The western boundary was excluded from the calculation. The units for the decadal salinity differences in (a), (c), (e), and (g) are PSS-78, and the units for the linear trends in (b), (d), (f), and (h) are latitude degrees per 10 years, with positive northward.

\subsection{Potential Impact of Data Sample Density}

To assess potential impacts of data sampling on our findings, we extend the analysis to the two supplemental data sets, the LEGOS and EN4 salinity products. The LEGOS SSS product is independent of the Ishii product 

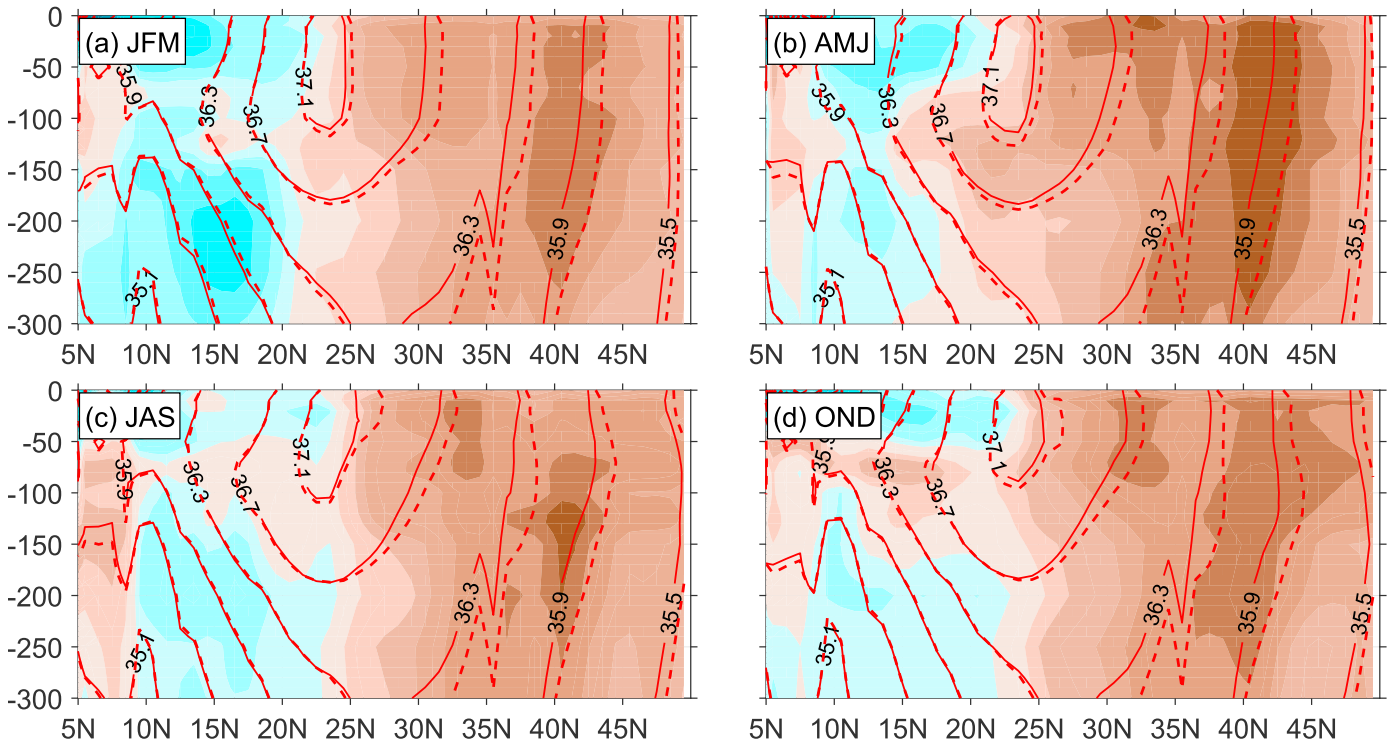

$5 \mathrm{~N} \quad 10 \mathrm{~N} 15 \mathrm{~N} 20 \mathrm{~N} 25 \mathrm{~N} 30 \mathrm{~N} 35 \mathrm{~N} 40 \mathrm{~N} 45 \mathrm{~N}$
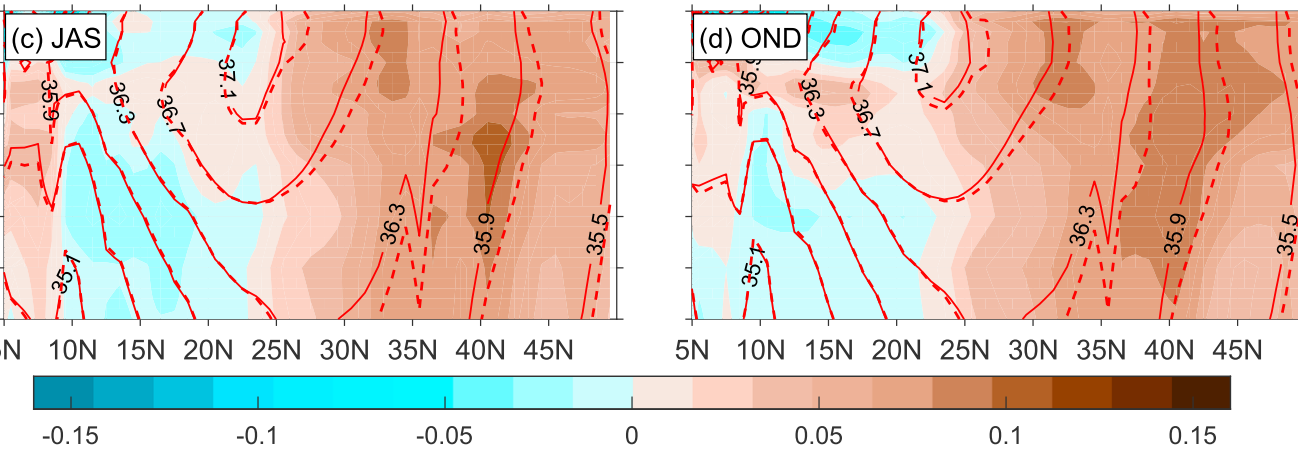

Figure 2. Decadal differences (2000-2009 minus 1980-1989; colors) in zonal-mean salinity (averaged between $80^{\circ} \mathrm{W}$ and $0^{\circ} \mathrm{W}$ ) in the upper $300 \mathrm{~m}$ and spatial isohaline shifts (contours) between the two decades for (a) winter (January-March), (c) spring (April-June), (e) summer (July-September), and (g) fall (October-December). The solid contours denote the isohalines averaged between 1980 and 1989, and the dashed contours denote the isohalines averaged between 2000 and 2009. The contour interval is 0.4. The units for the decadal salinity differences are PSS-78.

as the profiles collected by the IRD/LEGOS were not included in the Ishii product (Ishii et al., 2006). The results obtained from the two data sets (Figures $3 \mathrm{a}$ and $3 \mathrm{~b}$ ) agree with the finding derived from the Ishii data set; that is, the SSS has decreased on the equatorward side of the SSS-max and increased on the poleward side. Furthermore, the results are consistent with the Ishii-based results that the maximum poleward shift occurred in spring (Figures $3 \mathrm{c}$ and $3 \mathrm{~d}$ ), although the magnitude of the shift varies. The consistency across the three sets of salinity product indicates that the poleward expansion of the North Atlantic SSS-max and its maximum intensity in spring are robust decadal features.

It is worth noting that the patterns of SSS decadal difference anomalies are different among the three gridded SSS products (Figures 1 and 3). Magnitudes of the midlatitude SSS difference anomalies are generally higher in Ishii and EN4 than those in LEGOS. The objective mapping of LEGOS SSS analysis uses a Laplacian interpolation scheme, which minimizes the error on the mapped product. As a result, the LEGOS SSS produces a weaker amplitude (Reverdin et al., 2007). In addition, the number of underlying profiles in the LEGOS SSS is far more than those of the Ishii or EN4 during the 1980s, which could cause the discrepancy in the results. The products also differ in the spatial distribution of SSS anomalies. One reason for these differences could be the techniques used in objective mapping. The Ishii product has used a variational minimization technique (Derber \& Rosati, 1989), while the EN4 product has applied an objective analysis to bin qualitycontrolled profiles into gridded boxes by using the analysis correction scheme (Lorenc et al., 1991).

Using the EN4 salinity profiles, the spatial distribution of salinity sample density in the area of the SSS-max has been constructed (Figures $4 \mathrm{a}$ and 4b). The general increase in data density from the $1980 \mathrm{~s}$ to the $2000 \mathrm{~s}$ is observed (Figures 4c-4e), which is due to the availability of the Argo observations since the early 2000s. To further examine whether and how the identified poleward shift of the SSS-max can be affected by the change in data sample density, we have reconstructed the SSS fields for the period of 1980-2010 by using only the salinity profiles from the EN4 database that are not associated with the Argo program. The following procedures have been applied: removing profiles that differ from the seasonal cycle by more than 3 times the seasonal standard deviations and binning the profiles into $2^{\circ} \times 2^{\circ}$ boxes with a search radius of $2^{\circ}$. The resulting decadal-mean SSS in the 1980s and 2000s and the differences between the two decades are shown in Figures 5a, 5c, 5e, and 5g. Bar plots of the linear trends of the poleward expansion for the 36.3-37.1 

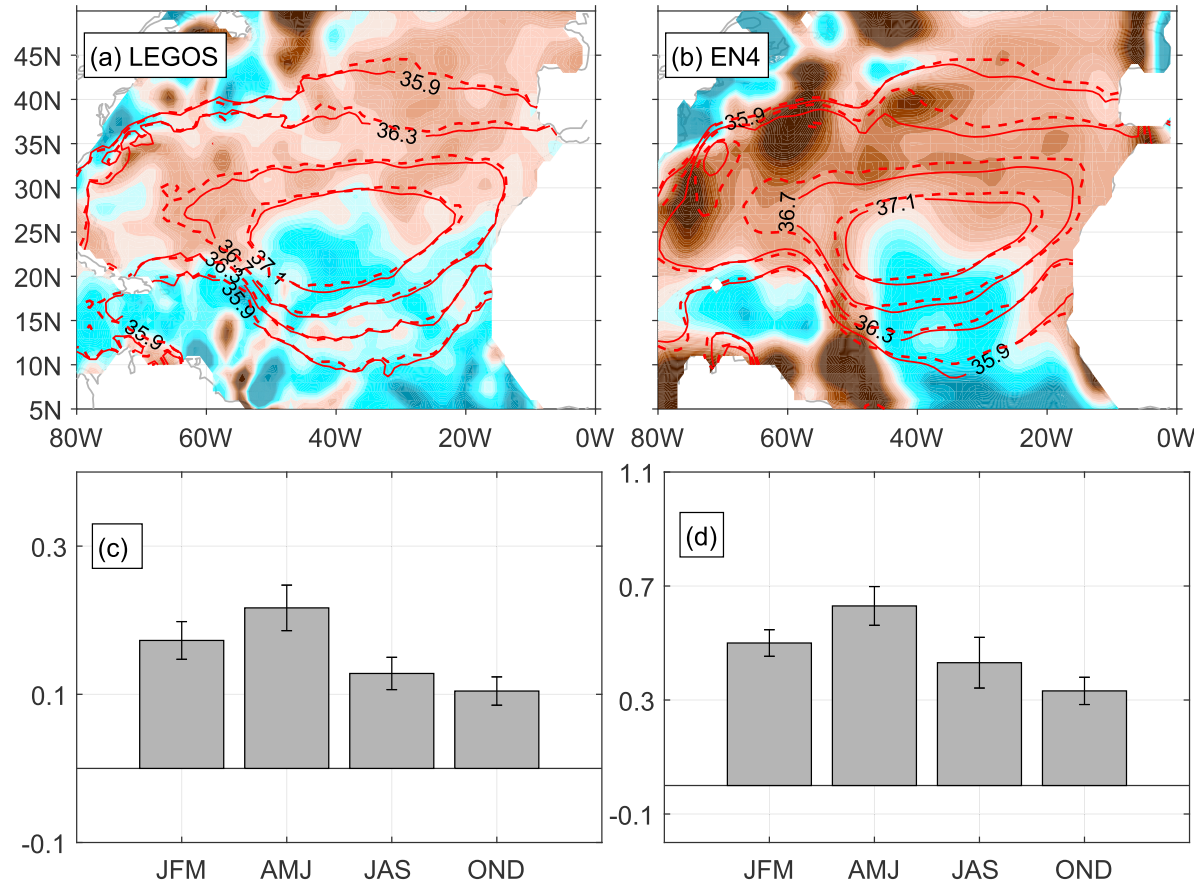

Figure 3. Decadal differences (2000-2009 minus 1980-1989; colors) in annual-mean salinity and the spatial isohaline shifts between the two decades derived from (a) LEGOS and (b) EN4. Bar plots of the averaged poleward expansion of the 35.9-37.1 isohalines (with 0.4 interval) on the poleward side of the SSS-max derived from (c) LEGOS and (d) EN4. The error bars denote the $90 \%$ confidence level. The units for the decadal salinity differences are PSS-78, and the units for the linear trend (c and d) are degrees per 10 years, where positive indicates northward.

isohalines located on the poleward side of the SSS-max are also shown (Figures 5b, 5d, 5f, and 5h). The patterns of the SSS decadal difference anomalies associated with the poleward expansion of the SSS-max are consistent with those based on the Ishii product (Figure 1) except that the magnitude of the latitudinal shift of the isohalines is weaker and the salinity anomalies are also weaker. It appears that the data sample density does not affect the finding of the poleward expansion of the SSS-max but does affect the quantification of the magnitude of the shift in the isohalines.

\subsection{Observed Decadal Changes in the STUW Properties}

The STUW is formed under the subtropical SSS-max by subduction. There are substantial changes in the North Atlantic STUW in the past decades when the SSS-max has expanded poleward. The patterns of the decadal changes in the STUW thickness are constructed for four seasons (Figures 6a-6d). Among the four seasons, the largest changes in STUW thickness occur in winter and spring, with the largest increase in STUW thickness located mainly to the north of $20-25^{\circ} \mathrm{N}$. The STUW expands both northward and westward, as denoted by black dots in Figures $6 \mathrm{a}$ and $6 \mathrm{~b}$. The westward intrusion into the Sargasso Sea leads to increases in STUW thickness of at least $10 \mathrm{~m}$. In winter, the decadal anomalies of the STUW thickness show two bands of anomalies with opposite signs between $20^{\circ} \mathrm{N}$ and $30^{\circ} \mathrm{N}$. The thickness of the STUW increases by $\sim 20 \mathrm{~m}$ between $28^{\circ} \mathrm{N}$ and $30^{\circ} \mathrm{N}$ but decreases by $10-20 \mathrm{~m}$ between $20^{\circ} \mathrm{N}$ and $28^{\circ} \mathrm{N}$. This pattern is a clear indication of the poleward shift in the isohalines (Figures 1 and 2). More positive STUW thickness anomalies are observed in spring than in winter. Positive STUW thickness anomalies exceed $20 \mathrm{~m}$ near the western boundary current and to the north of $25^{\circ} \mathrm{N}$ between $60^{\circ} \mathrm{W}$ and $10^{\circ} \mathrm{W}$, whereas negative STUW thickness anomalies are confined to the south of $25^{\circ} \mathrm{N}$. In general, the STUW thickness shows a stronger increase in spring than in winter. Greater increases in STUW thickness occur near the western boundary, and prominent decreases in STUW thickness occur near the eastern boundary. The reason for these phenomena is discussed in the next section.

The magnitudes of decadal changes in the STUW thickness in summer and fall are less than those in the first two seasons. In summer, the STUW thickens by $5-10 \mathrm{~m}$ to the north of $25^{\circ} \mathrm{N}$ between the western boundary 
(a) Number of S profiles during the 1980s

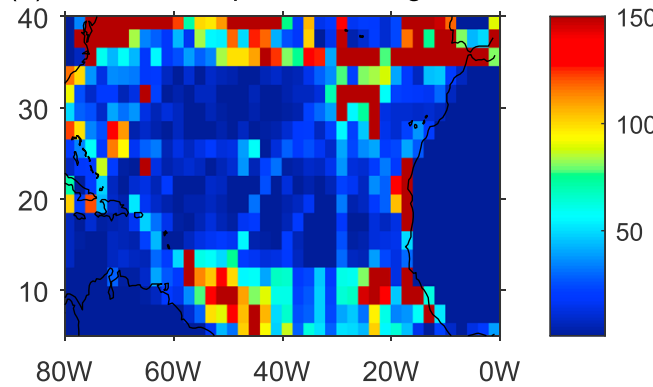

(b) Number of S profiles during the 2000s

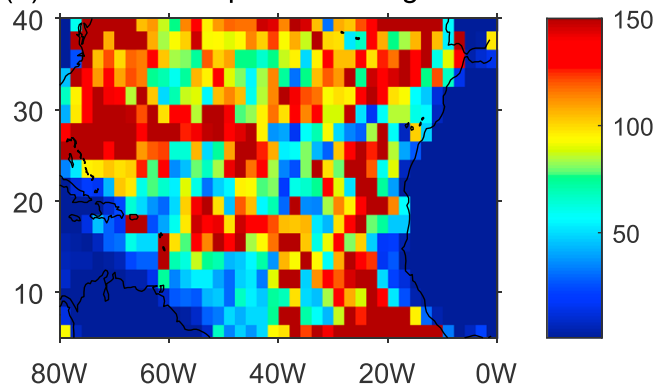

(c) The total number of $S$ profiles in each month

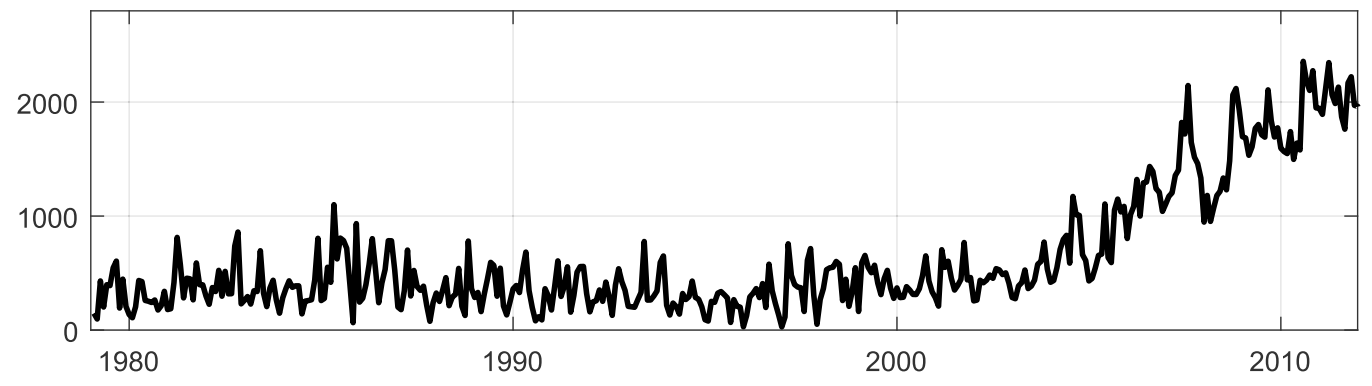

(d) Number of S profiles during the 1980s

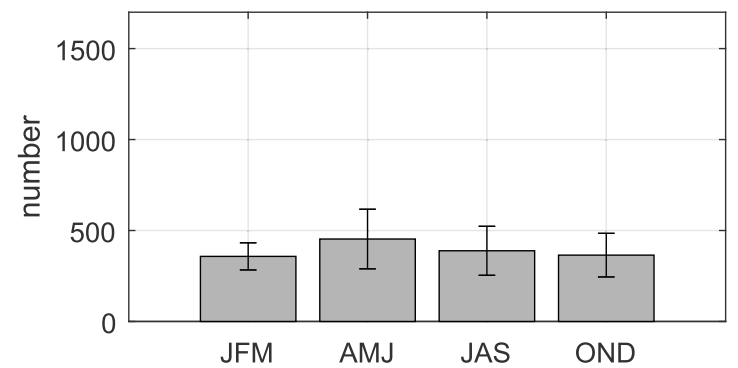

(e) Number of S profiles during the 2000s

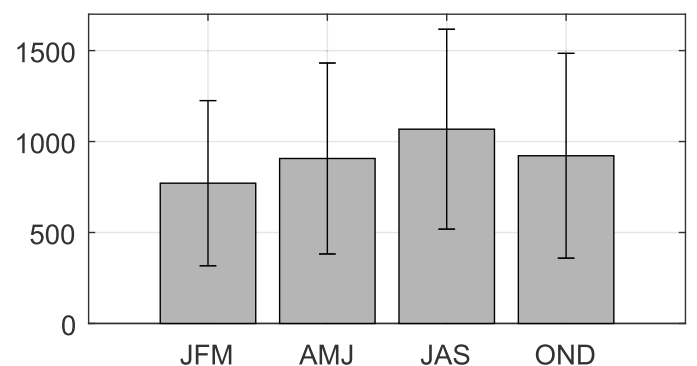

Figure 4. The horizontal distributions of the salinity profiles in each $2.5^{\circ} \times 2.5^{\circ}$ box during (a) the $1980 \mathrm{~s}(1980-1989)$ and (b) the 2000s (2000-2009). (c) The number of monthly salinity profiles within the entire region. The number of salinity profiles in each season during (d) the 1980s and (e) the 2000s. The bars denote the monthly average number of profiles in each season. The error bars denote one standard deviation. The salinity profiles are in situ salinity profiles collected by the Met Office Hadley Centre.

and $40^{\circ} \mathrm{W}$. In fall, the positive thickness anomalies shrink further toward the western boundary to the north of $25^{\circ} \mathrm{N}$. The total sum of the STUW thickness anomalies in fall is smaller than that in both winter and spring.

The seasonal variations of the decadal changes in the STUW thickness appear to be consistent with the seasonal variations of the changes in the STUW volume (Figure 6e). Decadal changes in the STUW volume within latitudes $20^{\circ} \mathrm{N}-30^{\circ} \mathrm{N}$ are quantified. We have also tested other domains but found that the results are not sensitive to slight changes in the spatial range. The annual-mean STUW volume increased by 0.21 $\pm 0.0210^{14} \mathrm{~m}^{3}$ per decade $(32 \pm 1 \%)$. The magnitude of the increase is not equal among the four seasons. The STUW volume increased by $0.26 \pm 0.0210^{14} \mathrm{~m}^{3}$ per decade $(41 \pm 1 \%)$ in winter, $0.31 \pm 0.0210^{14} \mathrm{~m}^{3}$ per decade $(48 \pm 1 \%)$ in spring, $0.18 \pm 0.0210^{14} \mathrm{~m}^{3}$ per decade $(27 \pm 1 \%)$ in summer, and $0.086 \pm 0.007$ $10^{14} \mathrm{~m}^{3}$ per decade $(13 \pm 9 \%)$ in fall. The maximum increase occurred in spring, which is consistent with the timing of the largest poleward shift at the surface. The decadal increase in the STUW volume in winter is slightly less than that in spring. In summer and fall, the volume increases are only half of those in winter and spring. It is worth noting that the positive STUW volume anomalies derived from the EN4 data set also show similar results (figures not shown here). Thus, the seasonal characteristics of the decadal increase in the STUW volume derived from the Ishii dataset are consistent among different data sets. 

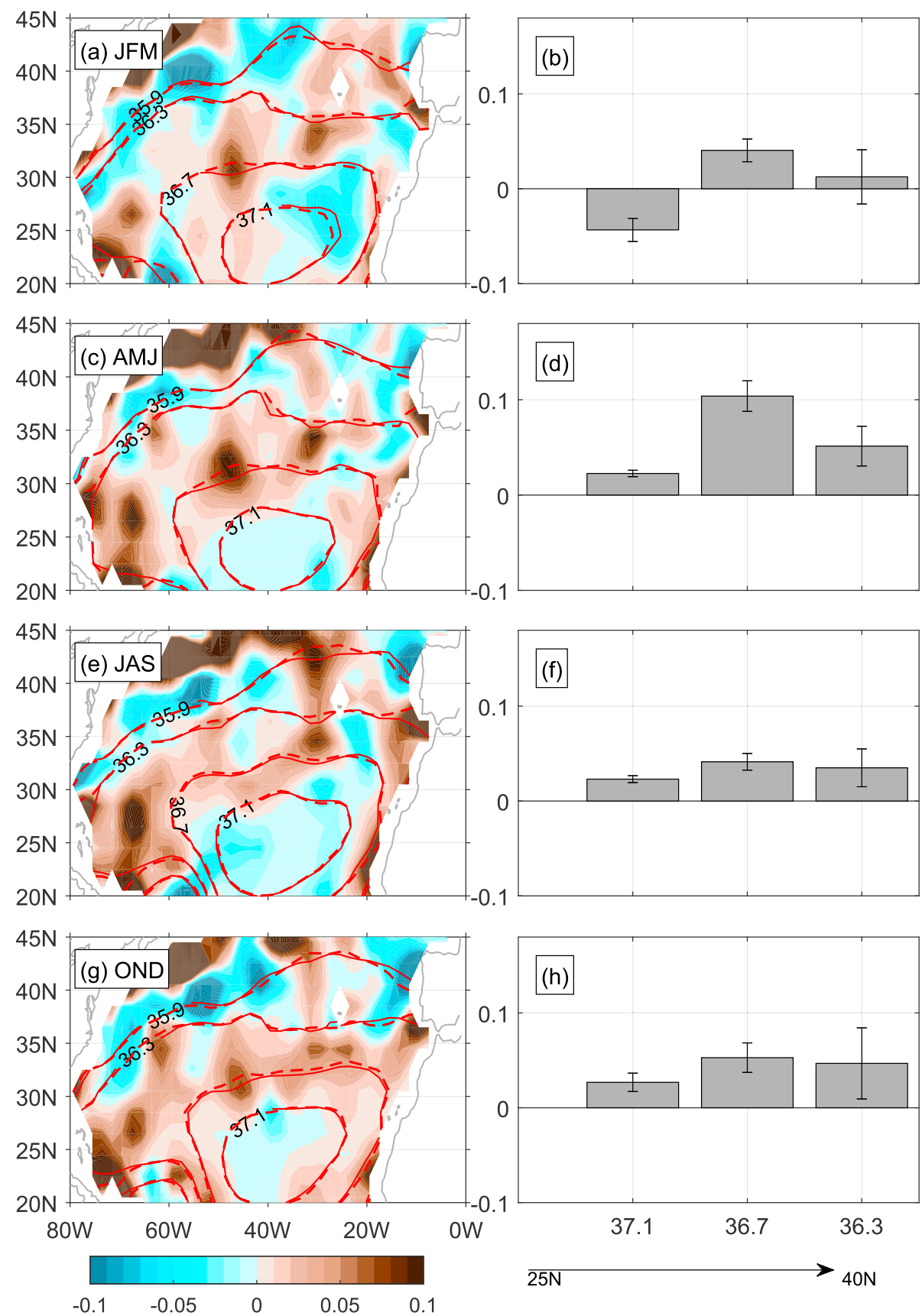

Figure 5. Decadal differences (2000-2009 minus 1980-1989; colors) in seasonally averaged surface salinity and the spatial isohaline shifts (contours) between the two decades for (a) winter (January-March), (c) spring (April-June),

(e) summer (July-September), and (g) fall (October-December). The gridded salinity map is constructed from the quality controlled EN4 profiles with exclusion of profiles from the Argo program. The solid contours denote the isohalines averaged between 1980 and 1989, and the dashed contours denote the isohalines averaged between 2000 and 2009. The contour interval is 0.4. Bar plots of the linear trends of the poleward expansion of the isohalines on the poleward side of the SSS-max for (b) winter, (d) spring, (f) summer, and (h) fall. The error bars denote the $90 \%$ confidence levels, which are derived from a two-tailed Student's $t$ test. The western boundary was excluded from the calculation. The units for the decadal salinity differences in (a), (c), (e), and (g) are PSS-78, and the units for the linear trends in (b), (d), (f), and (h) are latitude degrees per 10 years, with positive northward. 

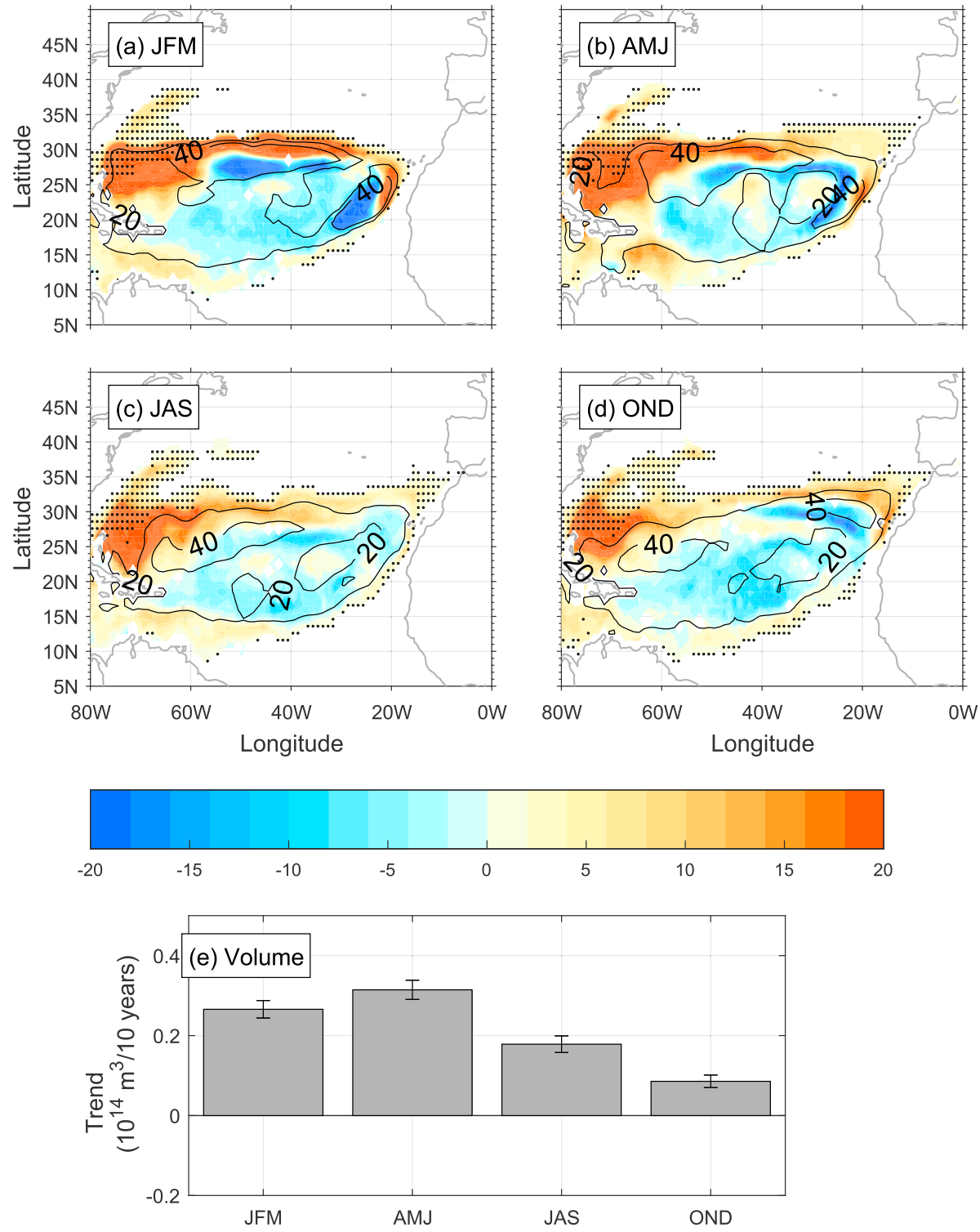

Figure 6. STUW thickness difference (2000s minus 1980s) in (a) winter (January-March), (b) spring (April-June), (c) summer (July-September), and (d) fall (October-December). (e) Linear trends of the STUW volume in the North Atlantic. The black lines in (a-d) denote the climatological STUW thickness, and the black dots denote the grid points at which the STUW exists during the 2000s but does not exist during the 1980s. The bars in (e) denote the linear fit of the STUW volume in each season, and the error bars denote the $90 \%$ confidence level. In the North Atlantic, the STUW properties are averaged between $80^{\circ} \mathrm{W}$ and $0^{\circ} \mathrm{W}$ and between $20^{\circ} \mathrm{N}$ and $30^{\circ} \mathrm{N}$.

\section{Mechanism}

The decadal changes in the STUW volume or thickness may be modulated by changes in production or dissipation. However, Yu et al. (2017) suspected that decadal changes in the volume and thickness of the STUW are solely due to the increased subduction rate. These authors found that the annual subduction rate had an upward trend from 1979 to 2012, which is consistent with thicker and saltier STUW. In this study, we find that the annual-mean subduction rate increases by $0.29 \pm 0.07 \mathrm{~Sv}$ per decade, which agrees with results from Yu et al. (2017). In this section, the decadal patterns of the subduction area/rate are analyzed, and how subduction connects the decadal changes in the SSS-max to the decadal changes in the STUW properties is explored. 
Subduction of the STUW within the North Atlantic occurs from January to April (efficient detrainment period; Qiu \& Huang, 1995); thus, the annual-mean subduction area/rate is divided into monthly components (from January to April). The climatological subduction rates in January and February are small, and the sum of their linear trends contributes to less than $15 \%$ of the decadal increase. As a result, this section focuses mainly on the decadal changes in the subduction area/rate in March and April.

\subsection{Expansion of the Subduction Zone}

The subduction area is that part of SSS-max in which water masses are detrained from the bottom of the mixed layer and are not entrained in the subsequent winter. The calculation of the subduction area is as follows: particles released from the bottom of the mixed layer within the SSS-max region are traced along the isopycnals for 1 year from the time it is subducted. If the water particle is submerged below the mixed layer after 1 year, the release point of the water particle is recorded as subduction area (Yu et al., 2017). The time series of subduction area (Figures $7 \mathrm{a}$ and $7 \mathrm{~b}$ ) are subtracted from their monthly means and then normalized by their standard deviations. The subduction areas during March and April show a significant upward trend, with rates of $(7.57 \pm 4.81) 10^{10} \mathrm{~m}^{2}$ per decade and $(9.24 \pm 3.92) 10^{10} \mathrm{~m}^{2}$ per decade, separately (Figures $7 \mathrm{a}$ and $7 \mathrm{~b}$ ). The increases in the subduction area agree with the decadal expansion of the SSS-max (Figure 1).

Figures $7 \mathrm{c}$ and $7 \mathrm{~d}$ explain the spatial connection between the expansion of the subduction area and that of the SSS-max. The black lines denote the isohalines, which indicate the STUW at the sea surface, the solid lines denote isohalines averaged between 1980 and 1989, and the dotted line denotes isohalines averaged between 2000 and 2009 .

In March, the subduction area spreads from $60^{\circ} \mathrm{W}$ to $70^{\circ} \mathrm{W}$, which is consistent with the westward expansion of the isohalines. The poleward side of the subduction area shifts toward the north (at a rate of $0.59 \pm 0.29^{\circ}$ per decade northward; magenta plus signs in Figure $7 \mathrm{c}$ ) between $50^{\circ} \mathrm{W}$ and $20^{\circ} \mathrm{W}$, whereas the equatorward side of the subduction area shows no changes between the 1980s and 2000s. The subduction area exhibits a much larger expansion in April than in March. During the 1980s, the subduction area mainly resides to the southeast of the subtropical gyre (the black plus signs in Figure 7d), whereas during the 2000s, the subduction area expands from $30^{\circ} \mathrm{W}$ to $70^{\circ} \mathrm{W}$ (the magenta plus signs in Figure $7 \mathrm{~d}$ ). The larger expansion of the subduction area in April is consistent with the larger expansion of the isohalines (Figure 1d) because the SSS-max confines the outcropping area of the STUW. The larger SSS-max expansion in early spring (April) results in a larger expansion in the subduction area.

\subsection{Increase in the Subduction Rate}

The time series of the subduction rate during March and April are subtracted from their monthly means and then normalized by their standard deviations (Figures 8a and 8b). The time series of the subduction area (Figures7a and 7b) and rate (Figures 8a and 8b) are nearly identical in March and April. The results confirm that the decadal changes in the subduction rate are controlled by the decadal changes in the subduction area, where the latter is associated with the decadal expansion of the SSS-max.

\subsubsection{The Time Series}

The subduction rate during March or April shows an upward trend (Figures $8 \mathrm{a}$ and $8 \mathrm{~b}$ ). The linear trend of the subduction rate in March is $1.24 \pm 0.50 \mathrm{~Sv}$ per decade, whereas the linear trend in April is $1.73 \pm 0.61 \mathrm{~Sv}$ per decade. Although the climatological subduction rate in March (7.8 Sv) over the analysis record is $50 \%$ larger than that in April (4.8 Sv), the long-term trend during March is 40\% smaller than that during April. Thus, the decadal increases in the subduction rate strongly depend on processes in early spring over the period of 1979-2012. The subduction rate in April has been doubled during the analysis record and contributed an increase of over $50 \%$ to its annual-mean value.

It is worth noting that lateral induction contributes a $90-96 \%$ increase in the total subduction rate during March and April. In contrast, vertical pumping contributes only 4-7\% of the subduction rate increase over the 1979-2012 period. Thus, lateral induction controls subduction rate changes and its monthly component (figures not shown here).

The monthly subduction rate (Figures $8 \mathrm{a}$ and $8 \mathrm{~b}$ ) anomalies are used here to explain the seasonal variations of the decadal increase in the STUW volume (Figure 6e). The subduction rate anomalies are positive in March and April. Therefore, the STUW volume also increases to the greatest extent during winter and 

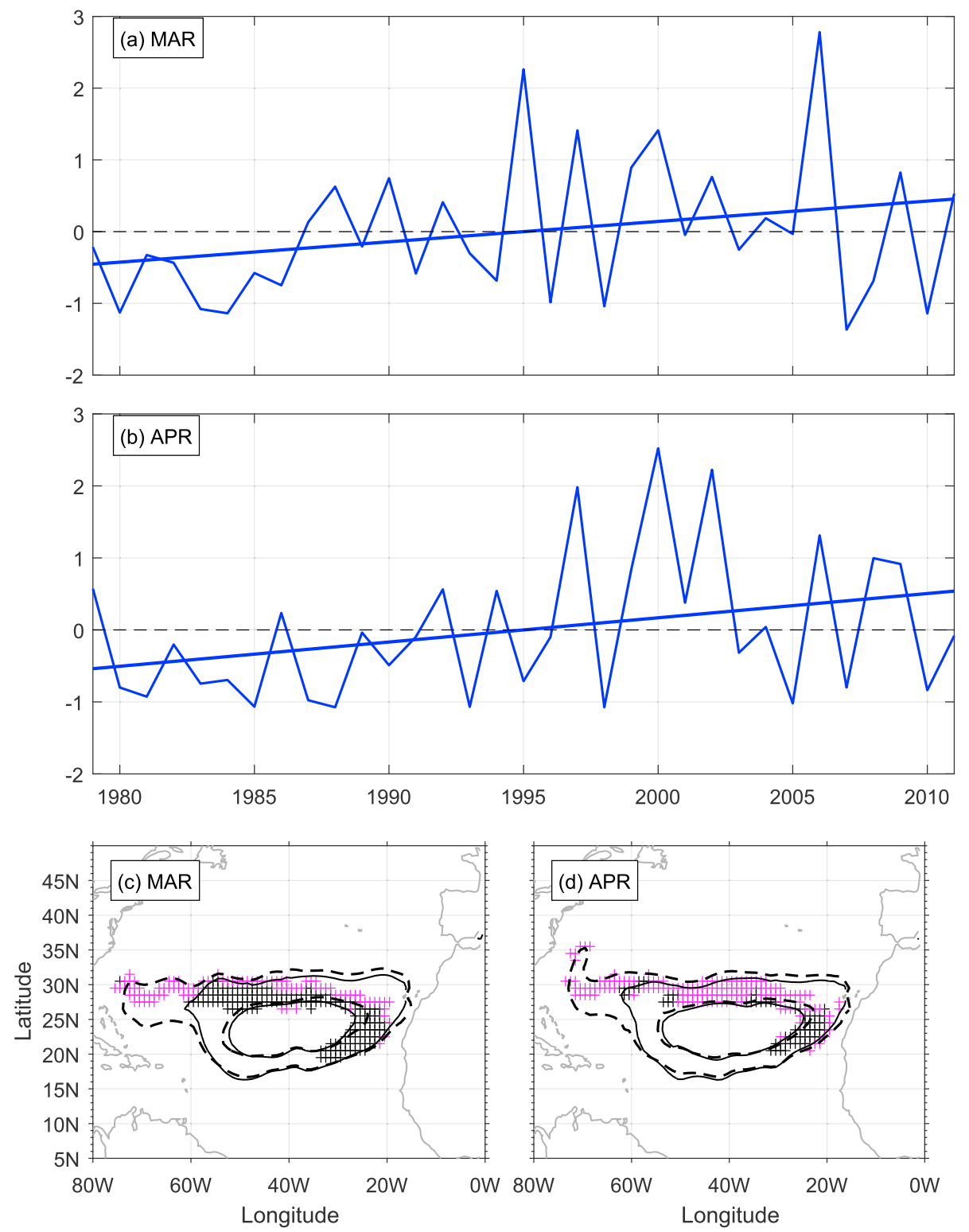

Figure 7. Time series of the normalized subduction area in (a) March and (b) April. The linear fit of the subduction area is drawn (straight solid line). The values of one standard deviation for the subduction area in March and April are 0.3 $\cdot 10^{12} \mathrm{~m}^{2}$ and $0.24 \cdot 10^{12} \mathrm{~m}^{2}$, respectively. Expansion of the subduction area in (c) March and (d) April. The black plus signs indicate the subduction area in 1980-1989, the magenta plus signs denote the expansion of the subduction area during 2000-2009, and the solid (1980-1989) and broken (2000-2009) black lines represent the spatial distributions of the isohalines (36.7 and 37.1).

spring. Moreover, the largest increases in the subduction rate during April are consistent with the largest increases in the STUW volume during spring. Since subduction does not occur during summer and fall, the STUW volume anomalies, which are preserved after stratification (Stommel, 1979), originate in winter and spring. Half of the anomalous STUW volume present during summer and fall is accumulated during winter and spring, whereas the other half might be advected away or dissipated (Blanke et al., 2002; Laurian et al., 2006; Qu et al., 2013). Laurian et al. (2006, 2009) used an analytical model and an ocean general circulation model to describe the dissipation of surface anomalies after production, and they found that nearly $34 \%$ of the surface anomalies could be kept at the subsurface after 6 years, which supports the theory of anomaly preservation after formation. 

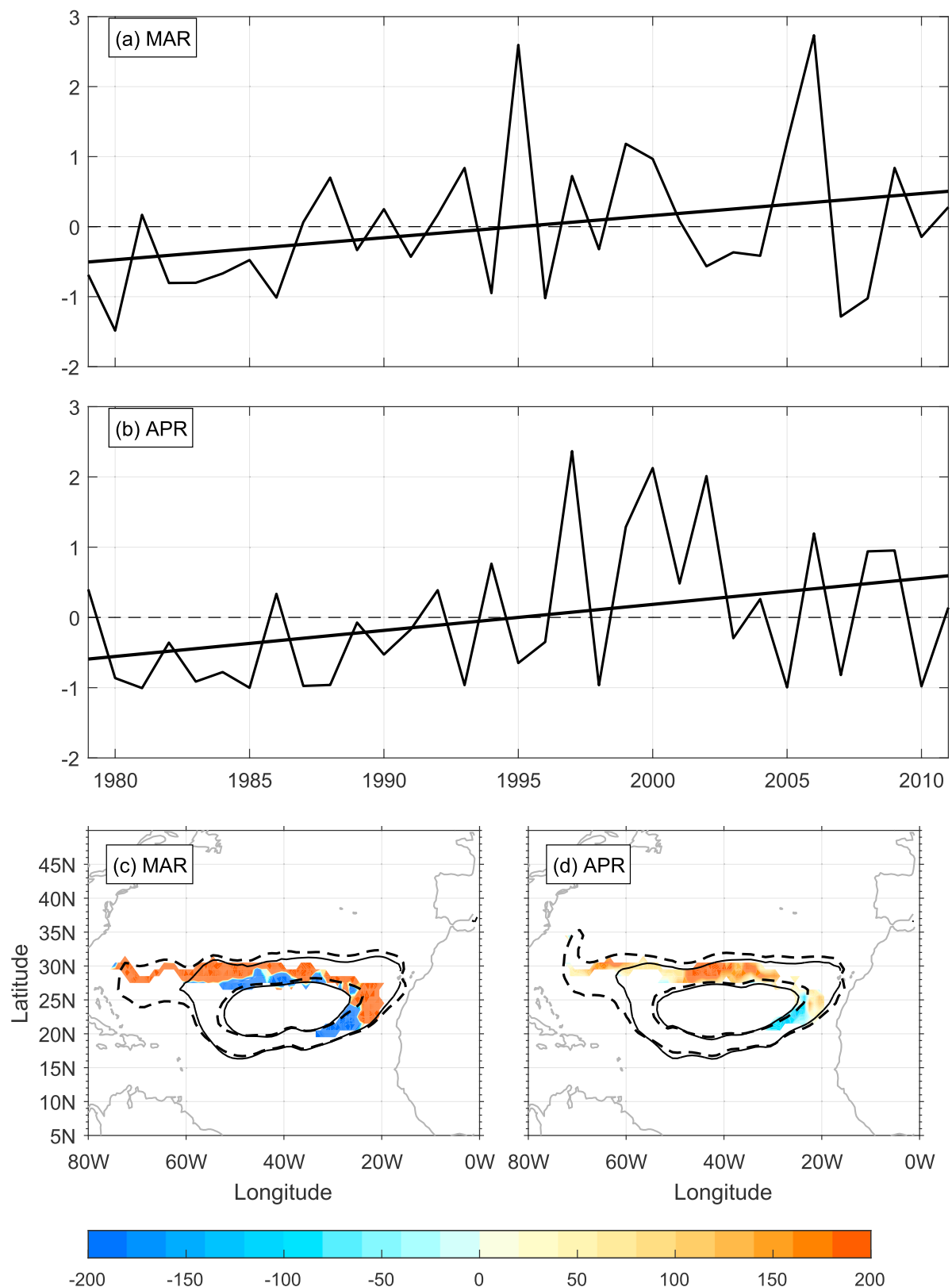

Figure 8. Time series of the normalized subduction rate in (a) March and (b) April. The linear fit of the subduction rate is drawn (straight solid line). The values of one standard deviation for the subduction rate in March and April are 3.88 and 4.68 Sv, respectively. The subduction rate difference (2000s minus 1980s) in (c) March and (d) April. The solid (1980-1989) and broken (2000-2009) black lines represent the spatial distributions of the isohalines (36.7 and 37.1). The spatial subduction rate units are $\mathrm{m} / \mathrm{year}$.

\subsubsection{The Spatial Pattern}

To fully understand the relationship between the seasonal variations of the STUW expansion and the monthly subduction increases, the spatial changes in the subduction rate (Figures 8c and 8d) and those in the STUW thickness (Figures 6a and $6 \mathrm{~b}$ ) are compared. The spatial patterns of the decadal changes in the STUW thickness in March and April are similar to those in winter and spring, respectively. Therefore, the subduction rates in March and April can be used to interpret the seasonal characteristics of the decadal changes in STUW thickness.

The spatial pattern of decadal changes in the subduction rate in March shows a poleward shift (Figure 8c). Positive subduction rate anomalies occur on the northern and western sides of the subduction area, and 


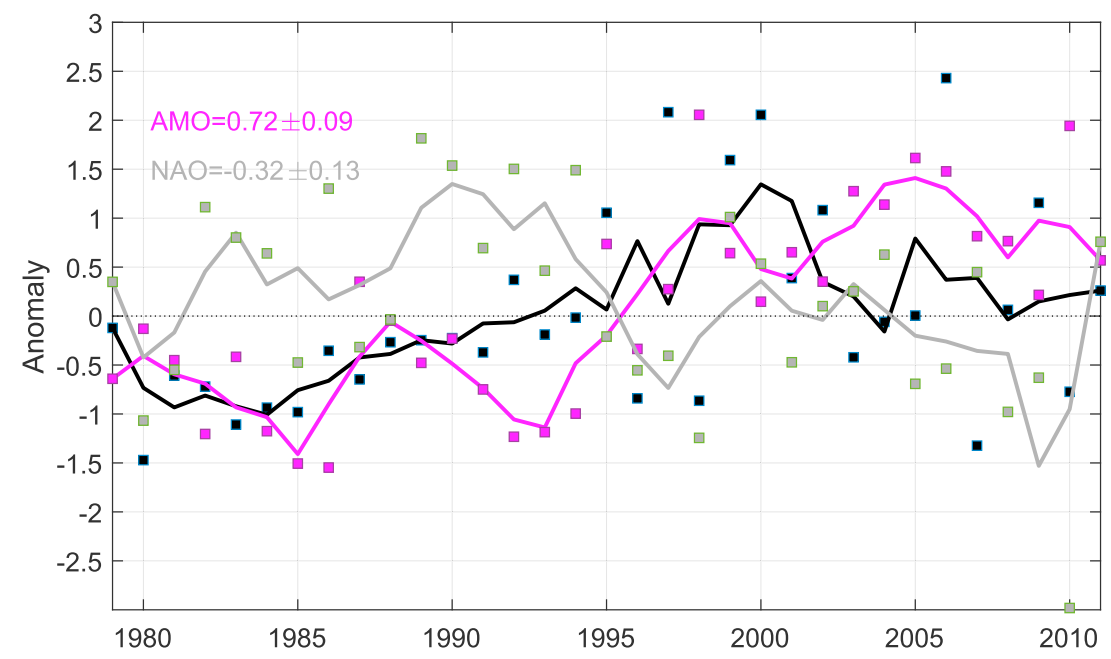

Figure 9. Anomalies of the normalized subduction rate (black dots) and annual-mean AMO (magenta dots) and NAO (gray dots) indexes in the North Atlantic. The three corresponding lines are the 3-year running means of their time series. The subduction rate is averaged from March to April. The linear trend (per 10 years) and the $90 \%$ confidence level for the two indexes are listed. The two indexes are subtracted from their climatological values and then divided by their standard deviations. One standard deviation for the AMO index is 0.18, and that for the NAO index is 0.39 .

negative anomalies are located on the equatorward side of the subduction area between $50^{\circ} \mathrm{W}$ and $25^{\circ} \mathrm{W}$. Thus, the subduction rate shows a dipole pattern across $28^{\circ} \mathrm{N}$, which is consistent with the dipole pattern of the STUW thickening between the two decades (Figure 6a). Furthermore, the subduction rate decreases over $100 \mathrm{~m} /$ year to the southeast, which is also consistent with a decrease in the STUW thickness at the same location. The STUW thickness anomalies could be advected downstream (Suga et al., 2000). Due to the Sverdrup relationship, the streamlines below the mixed layer point toward the equator (Blanke et al., 2002). As a result, the negative anomalies of the STUW thickness induced by a decrease in the subduction rate could spread toward the equator (Figure 6a).

In April, the subduction rate mainly shows a northwestward expansion (Figure 8d). The magnitudes of the positive subduction rate anomalies exceed $100 \mathrm{~m} /$ year to the north of $25^{\circ} \mathrm{N}$ and to the west of $30^{\circ} \mathrm{W}$. On the equatorward side of the subduction area, the subduction rate decreases, although its magnitude is less than $80 \mathrm{~m} /$ year. The subduction rate primarily increases in April, which can explain the STUW thickening observed in spring to the north of $28^{\circ} \mathrm{N}$. The observed decrease in the subduction rate to the south of $28^{\circ} \mathrm{N}$ in April is much smaller than that in March, which is also consistent with the smaller magnitude of the decrease in the STUW thickness therein.

During summer and fall, the STUW thickness anomalies are similar to those in the subduction seasons. After subduction, the STUW could persist for 5-10 years (Blanke et al., 2002; Inui et al., 2002; Qu et al., 2013; Zhang et al., 2003). Therefore, the decadal changes in the STUW thickness to the south of $25^{\circ} \mathrm{N}$ (or the positive anomalies to the north of $28^{\circ} \mathrm{N}$ and to the west of $60^{\circ} \mathrm{W}$ ) could be advected from upstream areas during the previous seasons.

In conclusion, the consistency between seasonal variations of the decadal increase in the STUW volume/thickness and monthly patterns of the subduction rate imply that the main driver underlying the seasonal pattern of decadal changes in the STUW is subduction.

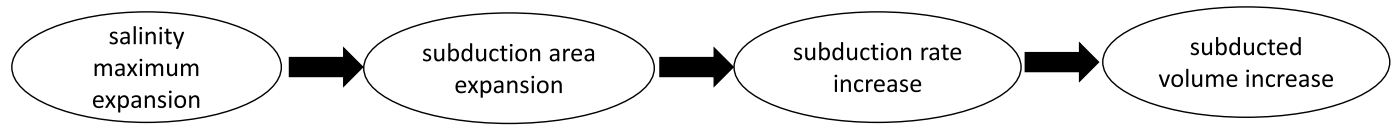

Figure 10. Schematic diagram illustrating the increase in the STUW volume led by the expansion of the SSS-max. 


\section{Discussion and Conclusions}

The decadal increases in the subduction rate could result from the long-term trends of air-sea buoyancy fluxes or momentum fluxes. Air-sea flux changes can be tracked using air-sea decadal or multidecadal oscillation indexes. Previous studies proposed that the North Atlantic Oscillation (NAO; Barnston \& Livezey, 1987; Chen \& van den Dool, 2003) could modulate the production rate of the STUW in the North Atlantic on an interannual timescale (O'Connor et al., 2005; Qu et al., 2016). The Atlantic Multidecadal Oscillation (AMO; Enfield et al., 2001; Schlesinger \& Ramankutty, 1994) is reported to have played a role in the decadal changes in the STUW $\mathrm{O}_{2}$ (Montes et al., 2016), which may be associated with decadal changes in the STUW production. Furthermore, the AMO is positively correlated with the decadal changes in the SSS within the North Atlantic subtropical gyre (Friedman et al., 2017). Thus, decadal changes in both indexes linked to the changes in the atmospheric forcings could indicate decadal changes in the STUW production. Here, we discuss how the subduction rate of the STUW changes in accordance with changes in the NAO or the AMO from 1979 to 2012. The NAO and AMO indexes are averaged annually, and the subduction rate is averaged from March to April.

The subduction rate shows a consecutive increase from 1979 to 2000 (Figure 9), and it has maintained a relatively high magnitude since 2000. The AMO (Figure 9) index shows an upward trend, which is similar to the subduction rate trend: an increase from 1979 to 1998 and a consistent relatively high magnitude after 1999. The NAO index (Figure 9) shows the opposite pattern, with a positive NAO occurring before 1995 and a negative NAO occurring after 1996. The linear trends and 90\% confidence levels of the NAO/AMO indexes are listed in Figure 9. Both the subduction rate and the AMO index show significant positive linear trends from 1979 to 2012. However, the NAO index shows a significant negative linear trend. The AMO index is not consistent with the subduction rate on an interannual scale; however, at a lower frequency, that is, a decadal scale, the two are consistent. We calculate the correlations between the two indexes and the subduction rate separately. The AMO and the subduction rate are positively correlated, whereas the NAO index is nonsignificant and negatively correlated with the subduction rate. Recent studies have shown that the NAO might not regulate the decadal change in the subtropical gyre (Barrier et al., 2013), which could explain why the correlation between the subduction rate and the NAO index is not significant. In conclusion, the AMO index shows greater coherency with the subduction rate than with the NAO index.

Figure 10 summarizes the main mechanism underlying the processes that associate the spatial changes in the SSS-max with the production of the STUW. The SSS-max displays poleward expansion, which leads to an increase in the subduction area and rate. The subduction rate increase then drives an increase in the STUW volume. The expansion of the SSS-max, which primarily occurs during spring, leads to an increase in the annual-mean subduction rate in early spring (April). Thus, this expansion leads to the largest increases in the STUW volumes and thicknesses occurring in spring among the four seasons.

The SSS-max in the North Atlantic shows the largest expansion to the north in spring and by $0.43 \pm 0.21^{\circ}$ per decade over the study period. The poleward expansion of the zonal mean subsurface isohalines (or salinification) on the poleward side of the SSS-max also primarily occurs during spring. The subsurface salinification during the analysis record is linked to STUW expansion. The annual-mean STUW volume increased by $0.21 \pm 0.0210^{14} \mathrm{~m}^{3}$ over the study period. Among the four seasons, the STUW volume shows the largest increase $\left(0.31 \pm 0.0210^{14} \mathrm{~m}^{3}\right.$ per decade, $\left.48 \pm 1 \%\right)$ in spring. Moreover, the STUW thickness on the poleward side of the SSS-max also shows the largest increases of 10-20 $\mathrm{m}$ in spring among all four seasons.

The seasonal variations of the decadal STUW volume/thickness increase can be explained by subduction. The annual subduction rate increased by $0.29 \pm 0.07 \mathrm{~Sv}$ per decade. The decadal increase in the subduction rate varies between months. The greatest contribution to the decadal increase in the annual-mean subduction rate of $1.73 \pm 0.61 \mathrm{~Sv}$ per decade occurs in April, which leads to a maximum subducted volume in spring. Furthermore, the spatial pattern of STUW thickening during spring is consistent with the increased subduction rate in April. Thus, the monthly subduction rate can explain the seasonal variations of the decadal STUW expansion. 
Finally, this study finds that the larger expansion of the SSS-max in early spring than in winter leads to a larger expansion in the subduction area in April than in March, and changes in the subduction area are equivalent to changes in the subduction rate. Therefore, the subduction rate shows a maximum increase in April.

The decadal increases in the subduction rate may be related to the AMO instead of the NAO. However, the linkage between the decadal changes in the AMO indexes and subduction rate still need to be investigated. The lateral induction (the first two terms in equation (3)) contributes to a 90-96\% increase in the total subduction rate during March and April. In contrast, vertical pumping (the last term in equation (3)) contributes only 4-7\% to the subduction rate increase over the 1979-2012 period. Thus, lateral induction controls the subduction rate changes (figures not shown here). According to equation (3), changes in lateral induction are determined by variations in the mixed layer depth, which could be related to wind anomalies $(\mathrm{Qu}$ et al., 2016) or buoyancy flux anomalies. In further research, we will seek to identify the exact processes that cause the decadal increase in the subduction rate.

\section{Acknowledgments}

Most of the work was conducted at the Woods Hole Oceanographic Institution, while H. Liu was a guest student sponsored by the China Scholarship Council (201506330001). H. Liu thanks Drs. Ruixin Huang and Xiangze Jin for discussions on the computation of the STUW formation and subduction rates. The Ishii subsurface salinity and temperature analysis data sets were downloaded from https://rda.ucar.edu/ datasets/ds285.3/. The EN4 data set is available at https://www.metoffice.gov. uk/hadobs/en4/download-en4-2-1. $\mathrm{html}$. The LEGOS SSS is accessible from http://www.legos.obs-mip.fr/observations/sss/datadelivery/products.The OAFlux vector wind analysis is available at http://oaflux.whoi.edu. The NAO index was downloaded from https://www.ncdc.noaa.gov/teleconnections/nao/. The AMO index is available at https://www.esrl.noaa.gov/ psd/data/timeseries/AMO/. X. Lin is supported by China's National Key Research and Development Projects (2016YFA0601803) in addition to the National Natural Science Foundation of China (41521091 and U1606402) and the Qingdao National Laboratory for Marine Science and Technology (2017ASKJ01).

\section{References}

Antonov, J. I., Levitus, S., \& Boyer, T. P. (2002). Steric sea level variations during 1957-1994: Importance of salinity. Journal of Geophysical Research, 107(C12), 8013. https://doi.org/10.1029/2001JC000964

Barnston, A. G., \& Livezey, R. E. (1987). Classification, seasonality and persistence of low-frequency atmospheric circulation patterns. Monthly Weather Review, 115(6), 1083-1126. https://doi.org/10.1175/1520-0493(1987)115<1083:CSAPOL>2.0.CO;2

Barrier, N., Treguier, A.-M., Cassou, C., \& Deshayes, J. (2013). Impact of the winter North-Atlantic weather regimes on subtropical seasurface height variability. Climate Dynamics, 41(5-6), 1159-1171. https://doi.org/10.1007/s00382-012-1578-7

Blanke, B., Arhan, M., Lazar, A., \& Prévost, G. (2002). A Lagrangian numerical investigation of the origins and fates of the salinity maximum water in the Atlantic. Journal of Geophysical Research, 107(C10), 3163. https://doi.org/10.1029/2002JC001318

Boyer, T. P., Levitus, S., Antonov, J., Locarnini, R., \& Garcia, H. (2005). Linear trends in salinity for the World Ocean, $1955-1998$. Geophysical Research Letters, 32, L01604. https://doi.org/10.1029/2004GL021791

Chen, W. Y., \& van den Dool, H. (2003). Sensitivity of teleconnection patterns to the sign of their primary action center. Monthly Weather Review, 131(11), 2885-2899. https://doi.org/10.1175/1520-0493(2003)131<2885:SOTPTT>2.0.CO;2

Curry, R., Dickson, B., \& Yashayaev, I. (2003). A change in the freshwater balance of the Atlantic Ocean over the past four decades. Nature, 426(6968), 826-829. https://doi.org/10.1038/nature02206

Derber, J., \& Rosati, A. (1989). A global oceanic data assimilation system. Journal of Physical Oceanography, 19(9), 1333-1347. https://doi. org/10.1175/1520-0485(1989)019<1333:AGODAS>2.0.CO;2

Durack, P. J., \& Wijffels, S. E. (2010). Fifty-year trends in global ocean salinities and their relationship to broad-scale warming. Journal of Climate, 23(16), 4342-4362. https://doi.org/10.1175/2010JCLI3377.1

Durack, P. J., Wijffels, S. E., \& Matear, R. J. (2012). Ocean salinities reveal strong global water cycle intensification during 1950 to 2000. Science, 336(6080), 455-458. https://doi.org/10.1126/science.1212222

Enfield, D. B., Mestas-Nuñez, A. M., \& Trimble, P. J. (2001). The Atlantic multidecadal oscillation and its relation to rainfall and river flows in the continental U.S. Geophysical Research Letters, 28(10), 2077-2080. https://doi.org/10.1029/2000GL012745

Friedman, A. R., Reverdin, G., Khodri, M., \& Gastineau, G. (2017). A new record of Atlantic sea surface salinity from 1896 to 2013 reveals the signatures of climate variability and long-term trends. Geophysical Research Letters, 44, 1866-1876. https://doi.org/10.1002/ 2017GL072582

Fyfe, J. C. (2003). Extratropical Southern Hemisphere cyclones: Harbingers of climate change? Journal of Climate, 16(17), $2802-2805$. https://doi.org/10.1175/1520-0442(2003)016<2802:ESHCHO>2.0.CO;2

Good, S. A., Martin, M. J., \& Rayner, N. A. (2013). EN4: Quality controlled ocean temperature and salinity profiles and monthly objective analyses with uncertainty estimates. Journal of Geophysical Research: Oceans, 118, 6704-6716. https://doi.org/10.1002/ 2013JC009067

Grodsky, S. A., Carton, J. A., \& Bingham, F. M. (2006). Low frequency variation of sea surface salinity in the tropical Atlantic. Geophysical Research Letters, 33, L14604. https://doi.org/10.1029/2006GL026426

Held, I. M., \& Soden, B. J. (2006). Robust responses of the hydrological cycle to global warming. Journal of Climate, 19(21), 5686-5699. https://doi.org/10.1175/JCLI3990.1

Hosoda, S., Suga, T., Shikama, N., \& Mizuno, K. (2009). Global surface layer salinity change detected by Argo and its implication for hydrological cycle intensification. Journal of Oceanography, 65(4), 579-586. https://doi.org/10.1007/s10872-009-0049-1

Hu, Y., \& Fu, Q. (2007). Observed poleward expansion of the Hadley circulation since 1979. Atmospheric Chemistry and Physics, 7(19), 5229-5236. https://doi.org/10.5194/acp-7-5229-2007

Hu, Y., Zhou, C., \& Liu, J. (2011). Observational evidence for poleward expansion of the Hadley circulation. Advances in Atmospheric Sciences, 28(1), 33-44. https://doi.org/10.1007/s00376-010-0032-1

Hudson, R., Andrade, M., Follette, M., \& Frolov, A. (2006). The total ozone field separated into meteorological regimes-Part II: Northern Hemisphere mid-latitude total ozone trends. Atmospheric Chemistry and Physics, 6(12), 5183-5191. https://doi.org/10.5194/ acp-6-5183-2006

Inui, T., Lazar, A., Malanotte-Rizzoli, P., \& Busalacchi, A. (2002). Wind stress effects on subsurface pathways from the subtropical to tropical Atlantic. Journal of Physical Oceanography, 32(8), 2257-2276. https://doi.org/10.1175/1520-0485(2002)032<2257:WSEOSP>2.0. $\mathrm{CO} ; 2$

Ishii, M., Kimoto, M., Sakamoto, K., \& Iwasaki, S.-I. (2006). Steric sea level changes estimated from historical ocean subsurface temperature and salinity analyses. Journal of Oceanography, 62(2), 155-170. https://doi.org/10.1007/s10872-006-0041-y

Lago, V., Wijffels, S. E., Durack, P. J., Church, J. A., Bindoff, N. L., \& Marsland, S. J. (2015). Simulating the role of surface forcing on observed multidecadal upper ocean salinity changes. Journal of Climate. https://doi.org/10.1175/JCLI-D-15-0519.1 
Laurian, A., Lazar, A., \& Reverdin, G. (2009). Generation mechanism of spiciness anomalies: An OGCM analysis in the North Atlantic subtropical gyre. Journal of Physical Oceanography, 39(4), 1003-1018. https://doi.org/10.1175/2008JPO3896.1

Laurian, A., Lazar, A., Reverdin, G., Rodgers, K., \& Terray, P. (2006). Poleward propagation of spiciness anomalies in the North Atlantic Ocean. Geophysical Research Letters, 33, L13603. https://doi.org/10.1029/2006GL026155

Lorenc, A., Bell, R., \& Macpherson, B. (1991). The Meteorological Office analysis correction data assimilation scheme. Quarterly Journal of the Royal Meteorological Society, 117(497), 59-89. https://doi.org/10.1002/qj.49711749704

McCabe, G. J., Clark, M. P., \& Serreze, M. C. (2001). Trends in Northern Hemisphere surface cyclone frequency and intensity. Journal of Climate, 14(12), 2763-2768. https://doi.org/10.1175/1520-0442(2001)014<2763:TINHSC >2.0.CO;2

Monterey, G. I., \& Levitus, S. (1997). Seasonal variability of mixed layer depth for the world ocean: U.S. Department of Commerce, National Oceanic and Atmospheric Administration, National Environmental Satellite, Data, and Information Service.

Montes, E., Muller-Karger, F., Cianca, A., Lomas, M. W., Lorenzoni, L., \& Habtes, S. (2016). Decadal variability in the oxygen inventory of North Atlantic Subtropical Underwater captured by sustained, long-term oceanographic time-series observations. Global Biogeochemical Cycles, 30, 460-478. https://doi.org/10.1002/2015GB005183

O'Connor, B. M., Fine, R. A., \& Olson, D. B. (2005). A global comparison of subtropical underwater formation rates. Deep Sea Research Part I: Oceanographic Research Papers, 52(9), 1569-1590. https://doi.org/10.1002/2015GB005183

Qiu, B., \& Huang, R. X. (1995). Ventilation of the North Atlantic and North Pacific: Subduction versus obduction. Journal of Physical Oceanography, 25(10), 2374-2390. https://doi.org/10.1175/1520-0485(1995)025<2374:VOTNAA>2.0.CO;2

Qu, T., Gao, S., \& Fukumori, I. (2013). Formation of salinity maximum water and its contribution to the overturning circulation in the North Atlantic as revealed by a global general circulation model. Journal of Geophysical Research: Oceans, 118, 1982-1994. https://doi. org/10.1002/jgrc.20152

Qu, T., Zhang, L., \& Schneider, N. (2016). North Atlantic Subtropical Underwater and its year-to-year variability in annual subduction rate during the Argo period. Journal of Physical Oceanography. https://doi.org/10.1175/JPO-D-15-0246.1

Reverdin, G., Kestenare, E., Frankignoul, C., \& Delcroix, T. (2007). Surface salinity in the Atlantic Ocean (30 S-50 N). Progress in Oceanography, 73(3-4), 311-340. https://doi.org/10.1016/j.pocean.2006.11.004

Roemmich, D., \& Gilson, J. (2009). The 2004-2008 mean and annual cycle of temperature, salinity, and steric height in the global ocean from the Argo Program. Progress in Oceanography, 82(2), 81-100. https://doi.org/10.1016/j.pocean.2009.03.004

Scheff, J., \& Frierson, D. (2012). Twenty-first-century multimodel subtropical precipitation declines are mostly midlatitude shifts. Journal of Climate, 25(12), 4330-4347. https://doi.org/10.1175/JCLI-D-11-00393.1

Schlesinger, M. E., \& Ramankutty, N. (1994). An oscillation in the global climate system of period 65-70 years. Nature, 367(6465), 723-726. https://doi.org/10.1038/367723a0

Schmitt, W. R., \& Blair, A. (2015). A river of salt. Oceanography, 28(1), 40-45. https://doi.org/10.5670/oceanog.2015.04

Siler, N., Roe, G. H., \& Armour, K. C. (2018). Insights into the Zonal-Mean Response of the Hydrologic Cycle to Global Warming from a Diffusive Energy Balance Model. Journal of Climate, 31(18), 7481-7493. https://doi.org/10.1175/JCLI-D-18-0081.1

Skliris, N., Marsh, R., Josey, S. A., Good, S. A., Liu, C., \& Allan, R. P. (2014). Salinity changes in the World Ocean since 1950 in relation to changing surface freshwater fluxes. Climate Dynamics, 43(3-4), 709-736. https://doi.org/10.1007/s00382-014-2131-7

Stommel, H. (1979). Determination of water mass properties of water pumped down from the Ekman layer to the geostrophic flow below. Proceedings of the National Academy of Sciences, 76(7), 3051-3055. https://doi.org/10.1073/pnas.76.7.3051

Suga, T., Kato, A., \& Hanawa, K. (2000). North Pacific Tropical Water: Its climatology and temporal changes associated with the climate regime shift in the 1970s. Progress in Oceanography, 47(2-4), 223-256. https://doi.org/10.1016/S0079-6611(00)00037-9

Terray, L., Corre, L., Cravatte, S., Delcroix, T., Reverdin, G., \& Ribes, A. (2012). Near-surface salinity as nature's rain gauge to detect human influence on the tropical water cycle. Journal of Climate, 25(3), 958-977. https://doi.org/10.1175/JCLI-D-10-05025.1

Yang, H., Lohmann, G., Wei, W., Dima, M., Ionita, M., \& Liu, J. (2016). Intensification and poleward shift of subtropical western boundary currents in a warming climate. Journal of Geophysical Research: Oceans, 121, 4928-4945. https://doi.org/10.1002/2015JC011513

$\mathrm{Yu}, \mathrm{L} .$, \& Jin, X. (2014). Insights on the OAFlux ocean surface vector wind analysis merged from scatterometers and passive microwave radiometers (1987 onward). Journal of Geophysical Research: Oceans, 119, 5244-5269. https://doi.org/10.1002/2013JC009648

Yu, L., Jin, X., \& Liu, H. (2017). Poleward shift in ventilation of the North Atlantic Subtropical Underwater. Geophysical Research Letters, 45, 258-266. https://doi.org/10.1002/2017GL075772

Zhang, D., McPhaden, M. J., \& Johns, W. E. (2003). Observational evidence for flow between the subtropical and tropical Atlantic: The Atlantic subtropical cells*. Journal of Physical Oceanography, 33(8), 1783-1797. https://doi.org/10.1175/2408.1

Zhou, Y., Xu, K. M., Sud, Y., \& Betts, A. (2011). Recent trends of the tropical hydrological cycle inferred from Global Precipitation Climatology Project and International Satellite Cloud Climatology Project data. Journal of Geophysical Research, 116, D09101. https://doi.org/10.1029/2010JD015197 